\title{
Applications of Geographical Information Systems in Understanding Spatial Distribution of Asthma
}

\author{
Mohammad A. Rob \\ University of Houston-Clear Lake, Houston, Texas, USA \\ rob@cl.uh.edu
}

\begin{abstract}
Geographical Information Systems (GIS) are becoming useful tools in making strategic decisions whenever data are found to have spatial distribution. Federal, state, and local governments are using GIS for assessment and planning in such areas as housing, healthcare, land use, natural resources, environmental monitoring and transportation. Companies are also using it to expand and consolidate existing businesses, perform market analysis, and to find optimum delivery routes. In this paper, we illustrate the usefulness of GIS in the analysis and presentation of spatially distributed asthma prevalence among school children (13-17 years) in the New York City area. To the best of our knowledge, this is the first presentation of asthma survey results distributed over the zip codes of a large city. Preliminary results show good correlation between asthma and poverty. They also correlate well with the spatial distribution of asthma hospitalization data. Results reveal an overall asthma prevalence of $\sim 16 \%$ as compared to the national average of $\sim 12 \%$ for a similar age group (5-17 years). When comparing asthma rates among the predominant racial groups of the city - Blacks and Hispanics are found to have a higher prevalence than Whites or Asians. The inner-city population shows a significantly higher asthma prevalence than those in the suburbs. This study shows our understanding of asthma prevalence in a dimension that could not have been possible prior to the availability of GIS. The results will help us making further decisions in planning for asthma research.
\end{abstract}

Keywords: GIS, Geographical Information Systems, asthma

\section{Introduction}

The use of Geographical Information Systems (GIS) has recently become popular (Lubenow \& Tolson, 2001; Francica, 2000; Hockstra \& Mattejat, 2002; Nemeth, 2001; Weigel \& Cao, 1999). GIS is used to understand, analyze, and manage spatially distributed data mapped to a geographical region. Although it started with the purpose of creating digital maps, it quickly became a valuable tool in the decisionmaking process for various industries. GIS has been widely accepted by government agencies. The majority of GIS applications are found in areas of natural resources, socio-economic demographics, and urban planning and transportation. However, increasingly applications are found in almost all disciplines

Material published as part of this journal, either on-line or in print, is copyrighted by the publisher of Informing Science. Permission to make digital or paper copy of part or all of these works for personal or classroom use is granted without fee provided that the copies are not made or distributed for profit or commercial advantage AND that copies 1) bear this notice in full and 2) give the full citation on the first page. It is permissible to abstract these works so long as credit is given. To copy in all other cases or to republish or to post on a server or to redistribute to lists requires specific permission and payment of a fee. Contact Editor@inform.nu to request redistribution permission. including: agriculture, business, engineering, environmental sciences, healthcare, law, and real estate (Fung, Kung, \& Barber, 1995; Walsham \& Sahay, 1999; Smith \& Webb, 1997; Saccomano, 1998). Vine, Degnan and Hanchette (1998) discuss advances in GIS and how the technology provides opportunities for environmental epidemiologists to study associations between environmental exposure and the spatial distribution of diseases. Jacquez (2000) discusses how GIS can 
be used to monitor disease outcomes, identify health risks, and design and implement intervention plans.

Many federal, state, and local government agencies are developing GIS datasets for spatial features such as roads, highways, rivers, lakes, parks, wet lands, hospitals, housing areas, traffic flows, mines, air pollution monitoring stations, oil fields, and pipelines (Texas General Land Office, 2002; Bureau of Transportation Statistics, 2002). In most cases, the spatial datasets also contain additional attributes reflecting demographic or socioeconomic conditions within a region. These data become extremely useful in making strategic decisions dealing with the government and business issues of the region. A typical GIS analyst will face various challenges incorporating non-spatial datasets to spatial datasets and finding ways to present the resulting datasets that are suitable for making conclusive decisions.

During the past decade, asthma became an epidemic especially among children in the United States (American Lung Association, 2002; Center for Disease Control, 2001). Most of the data available on asthma are based on the national survey and hospitalization discharge information. Although these data provide national statistics, they cannot be extrapolated for a particular city, county, or state. Furthermore, the data do not provide any geographical distribution of an asthma epidemic. In an attempt to understand the distribution of asthma in a localized area, an ongoing study is being performed in and around the New York City area. This paper provides some initial results of this study. GIS tools are used to manipulate asthma data with spatial zip code data and the resulting data is presented on a geographical map. The resulting output will not only become valuable for further research planning, it may also aid in making strategic decisions by healthcare agencies, healthcare providers, and the general public.

\section{Geographical Information Systems}

A Geographical Information System is a computerized system for input, storage, management, display and analysis of data that can be precisely linked to a geographic location. Typically, GIS datasets come as layers - there can be a layer for rivers, a layer for roads, and a layer for zip codes - all within a particular geographical boundary. A layer may consist of one or more features, which include points, lines, or boundaries. Various layers are superimposed to create a meaningful map. Each GIS layer has two views: a map view and a data view. The map acts as a visual representation of data, and a particular attribute of the dataset can be displayed on the map. The data view can be used to create a smaller dataset (or map) from a large dataset using a query tool.

A GIS layer dataset can also be combined with a user dataset to create a new layer as long as there is a common attribute in the two datasets. For example, Census 2000 non-GIS data can be joined with a zip code layer to create a new layer where population can be displayed for each zip code in the USA. GIS tools are available from a number of companies, but the ArcView software from the Environmental Systems Research Institute, Inc. (ESRI, 2000), is widely used throughout the world. Almost all government agencies in the USA started publishing data in the ArcView's shapefile format (Texas General Land Office, 2002; Bureau of Transportation Statistics, 2002).

\section{Asthma Prevalence and Death: A Case Study}

Asthma has become a public health concern, especially among children in the United States (American Lung Association, 2002; CDPH, 2000; Lara et al., 2002; Mann, 2000). More than 20 million Americans have asthma and about 5000 people die from asthma each year. African Americans (Blacks) are more susceptible to death from the disease than Caucasians (Whites), and females are more predisposed to asthma than are males among all age groups. Low-income and minority populations, as well as children in general have higher rates of asthma in comparison to other groups.

Each year, the National Center for Health Statistics (NCHS) surveys a representative sample of the noninstitutionalized civilian population of the country for all chronic diseases (Center for Disease Control, 
2002). According to the survey, asthma prevalence among persons aged $0-17$ years increased approximately $5 \%$ each year during 1980 - 1995. In 2001, 73 people per 1,000 or 20.3 million people had asthma. Asthma prevalence was found to be higher for children than adults; 87 per 1,000 children 0-17 years (6.3 million children), compared to 69 per 1,000 adults 18 years and over (14 million adults). When race/ethnicity is considered, asthma prevalence was about $10 \%$ higher among Blacks compared to Whites and about 40\% higher compared to Hispanics. Females had a 30\% higher prevalence compared to males. However, this pattern was reversed among children. The asthma prevalence rate for boys aged $0-17$ years (99 per 1,000) was over 30\% higher than the rate among girls (74 per $1,000)$. The NCHS also surveys health providers on patient visits to hospital emergency rooms, outpatient departments, doctor's offices, and hospitalizations for various illnesses. According to the report for the year 2000, there were 10.9 million outpatient visits for asthma to private physician offices and hospital clinics, which is equivalent to 379 visits per 10,000 people. Children aged $0-17$ years had a reported 4.6 million visits or a rate of 649 outpatient visits per 10,000 children; adults, 18 years and over, had a rate of 285 visits per 10,000 adults. Blacks had an office visit rate of $40 \%$ higher than whites, and females $10 \%$ higher than males. Similar trends were found for emergency room visits and hospitalizations for asthma.

The Center for Disease Controls (CDC) keeps track of all deaths (mortality data) in the United States through surveying hospital and funeral home death certificates. In 2000, 4,487 people died from asthma, 1.6 per 100,000 people. Among children asthma deaths are rare. In 2000, 223 children, aged $0-17$ years, died from asthma, 0.3 deaths per 100,000 children, as compared to 2.1 deaths per 100,000 adults, aged 18 and over. Data also shows substantial disparity of deaths among various age groups, races and genders - consistent with the survey results.

While little is known about the origin of asthma, tobacco smoke is found to be the leading modifiable agent for both the development of asthma in childhood and exacerbation of existing asthma. Ambient air pollutants such as ozone, sulfur dioxide, nitrogen dioxide, aerosols, and particulate matter also are found to exacerbate the condition as well (American Lung Association, 1997 \& 2001; Clark and Shay, 2002). A five-year study conducted on 3500 children, between the ages of 9 and 16, in 12 Southern California counties, found that children who compete in outdoor activities in polluted cities were more likely to be diagnosed with asthma than children in other areas (USC, 2002). The research also suggests that, contrary to conventional wisdom, ambient ozone is involved in the causation of asthma.

U.S. Department of Health and Human Services (DHHS, 2000) identified asthma as an epidemic of a chronic disease. In May 2000, DHHS published a strategic plan, Action Against Asthma, which calls for the determination of the causes of asthma and the development of interventions to prevent the onset of asthma. In addition, the plan calls for the reduction of burden for the people living with asthma, eliminate the disproportionate burden of asthma in minority populations and those living in poverty, track the disease, and assess the effectiveness of asthma intervention programs.

Current surveillance for asthma provides national estimates but cannot provide state or local level data on asthma. Also, this information does not reveal the detailed picture of how asthma varies from one location to another; data greatly needed for an effective public health response. Results that show a national trend may not be applicable to a localized area. Furthermore, national data may not cover all attributes necessary to understand asthma prevalence in a localized area. For example, New York has a large Asian population; however, neither the NCHS survey nor local hospital data identify Asians as a particular racial group. This lack of information is common to many large cities in the country.

Until recently, there was no tool to understand spatial distribution of data over a geographical region. GIS allows us to not only analyze and display asthma data in a spatial way, it also provides an opportunity to compare the data with other socioeconomic factors such as population density, average household income, and the percentage of minority population, in the same geographical domain. English et al. 
(1999) reported the use of GIS in exploring the incidences of hospital visits of asthmatic children living in low-income households located in close proximity to high-traffic areas in San Diego County. They suggest that higher traffic flows may be related to an increase in repeated medical visits for asthmatic children. Claudio et al. (1999) used a GIS tool to study spatial distribution of asthma hospitalization data in the New York City area. Their results suggest a direct relationship between asthma and poverty.

\section{Research Methodology}

To understand asthma prevalence in a localized area, a survey was performed on students in several middle and high schools of the New York City area (Institute on Climate and Planets, 2002). The project started in spring 2000 and continued for several semesters. In the questionnaire, students were asked about their age, gender, race, school and home zip codes, as well as whether they had asthma or not according to their belief. Details of the data formats can be found in the project Web site, http://icp.giss.nasa.gov/research/urbanmaap/asthma.html . A total of approximately 4300 students aged 13 through 17 were surveyed. ArcView 8.1 was used to plot spatial distribution of data over the New York City zip codes. In the study, a shapefile containing U.S. zip code boundaries was downloaded from the Web and only zip codes in the New York City area were used in the maps.

\section{Data Analysis}

The survey data were organized in a Microsoft Excel worksheet and were sorted by gender, race, and home zip code, creating a dataset for each category. We also identified the zip codes associated with the five inner-city boroughs of New York City (Manhattan, Bronx, Queens, Brooklyn, and Staten Island) and created a dataset for each. These datasets also included Long Island, a suburb of New York City. For each dataset, we then identified the number of people responding "Yes" and the number of people responding "No" to the question whether or not they had asthma. The asthma percentage for each category was then calculated. Chi-square was used to determine if the percentage of people with asthma in each borough was independent of the borough in which they live.

When summarizing data in terms of gender, race, and borough, there were several hundred $(400-2400)$ datasets available in each category. However, when the same is performed in terms of zip code, some zip codes were found to be represented poorly in terms of the number of respondents. In our final analysis, we thus considered only those zip codes that contained at least 10 respondents. After summarizing data by zip code in the Excel format, it was saved in a format readable by ArcView.

In our analysis, we used two different tools that come with ArcView, 8.1 - ArcCatalog and ArcMap. ArcCatalog was used to organize GIS data and files. ArcMap was used to join asthma data with the New York City zip code layer in order to create an asthma layer. The zip code from both datasets was used as the join attribute. ArcMap was also used to create a map using the New York City zip code layer and the asthma layer. The variation of asthma by zip code was displayed using a range of colors as well as displaying the asthma value for each zip code. To understand the relationship between asthma prevalence and socioeconomic condition of the people, we have also plotted poverty for the same New York City layer.

\section{Results and Discussion}

There were 4246 students who could be clearly identified as to whether or not they had asthma. The overall percentage of students having self-reported asthma, in the age group $13-17$ years, is found to be $\sim 16 \%$. According to the latest data available, this is somewhat higher than the national average for the similar age group (5-17 years), which was $~ 12 \%$ in 1999 (American Lung Association, 2002). Table1 presents asthma prevalence by gender in the New York City area. It shows that the males have a slightly 
higher asthma prevalence than females, consistent with the national statistics for the age group surveyed (Center for Disease Control, 2001).

Table 2 illustrates the prevalence of asthma by race. It also includes the Census 2000 population data for children under 18 years of age (New York Department of Planning, 2002). As seen by the total survey respondents in various racial groups, the four predominant groups - white, Black, Hispanic, and Asian

\begin{tabular}{|l|r|r|r|}
\hline Gender & Total Surveyed & \# Asthma & $\%$ Asthma \\
\hline Male & 1830 & 312 & 17.05 \\
\hline Female & 2415 & 365 & 15.11 \\
\hline & & & \\
\hline Total & $\mathbf{4 2 4 5}$ & $\mathbf{6 7 7}$ & $\mathbf{1 5 . 9 5}$ \\
\hline
\end{tabular}

Table 1: Prevalence of asthma by gender in the New York City area

- are shown to be well represented in the overall survey. However, considering the Census population in each category, the Asian category is found to be more representative than the others. The table clearly presents a disparity of asthma prevalence between various racial groups. For example, the Asians are found to have the lowest asthma prevalence among the four predominant groups while Hispanics have the highest. Also, the disparity between Hispanic and

\begin{tabular}{|l|r|r|r|r|}
\hline Race & $\begin{array}{l}\text { 2000 Population } \\
\text { Under 18 years }\end{array}$ & $\begin{array}{l}\text { Total Sur- } \\
\text { veyed }\end{array}$ & \# Asthma & \% Asthma \\
\hline White & 455,703 & 769 & 100 & 13 \\
\hline Black & 568,295 & 1,253 & 215 & 17.16 \\
\hline Hispanic & 661,346 & 833 & 163 & 19.57 \\
\hline Asian & 168,817 & 933 & 107 & 11.47 \\
\hline Native American & 6,412 & 19 & 6 & 31.58 \\
\hline Multi-Ethnic & 60,704 & 141 & 43 & 30.5 \\
\hline Other & 18,992 & 210 & 29 & 13.81 \\
\hline & & & & \\
\hline Total & $\mathbf{1 , 9 4 0 , 2 6 9}$ & $\mathbf{4 , 1 5 8}$ & $\mathbf{6 6 3}$ & $\mathbf{1 5 . 9 5}$ \\
\hline
\end{tabular}

Table 2: Prevalence of asthma by race in the New York City area

Blacks is in contrast to the re-

sults found in the national survey, which consistently reported Blacks having a higher asthma prevalence than Hispanics.

Table 3 shows asthma prevalence in various boroughs of New York City. Again, it includes the Census 2000 population for children under 18 years of age. Note that there are disparate numbers of respondents in various boroughs - Manhattan and Queens represented better than the others, and Staten Island is poorly represented. There are statistically significant differences in the rates of asthma between the five boroughs and Long Island ( $\mathrm{p}$ value $=0.0113$ ). Long Island shows significantly lower asthma rates than the inner-city boroughs. Chi-square analysis, excluding Long Island, yields statistically significant differences between the remaining boroughs ( $\mathrm{p}$ value $=0.0334$ ). Among the five boroughs, Manhattan has a slightly higher asthma prevalence than the others. This is opposite to what is expected when considering the living conditions of the overall population. Historical data of the NCHS survey, hospital discharges, and mortality data suggest a direct relationship between asthma and poverty (Claudio et al., 1999). The New York State's poverty rate (13.6) is almost $20 \%$ higher than the national poverty rate (11.3) and it

\begin{tabular}{|l|r|r|r|r|r|}
\hline Borough & $\begin{array}{l}\text { 2000 Population } \\
\text { Under 18 years }\end{array}$ & $\begin{array}{l}\text { \% People Un- } \\
\text { der 18 Below } \\
\text { Poverty Level }\end{array}$ & $\begin{array}{l}\text { Total } \\
\text { Surveyed }\end{array}$ & \# Asthma & \% Asthma \\
\hline Manhattan & 257,916 & 32 & 1317 & 247 & 18.75 \\
\hline Bronx & 397,372 & 41.7 & 430 & 67 & 15.58 \\
\hline Queens & 509,224 & 19.2 & 1654 & 239 & 14.45 \\
\hline Brooklyn & 662,499 & 34.2 & 712 & 111 & 15.59 \\
\hline Staten Island & 113,258 & 13.5 & 21 & 3 & 14.29 \\
\hline Long Island & & & 112 & 10 & 8.93 \\
\hline Total & $\mathbf{1 , 9 4 0 , 2 6 9}$ & & 4246 & 677 & 15.94 \\
\hline
\end{tabular}

Table 3: Prevalence of asthma by borough in the New York City area 
is much higher than the neighboring states of Connecticut (6.3) and New Jersey (8.1) (Fiscal Policy Institute, 2001). The number is even higher for the New York City area, which is $21.2 \%$ for all age groups and $30.3 \%$ for children below 18 years of age (New York Department of Planning, 2002). The high poverty among children might be responsible for a higher asthma rate found in the current study. Bronx and Brooklyn, in general, have higher poverty rates than those of Manhattan and Queens (Table 3 ), yet the overall asthma results do not support that assumption. However, the upper part of Manhattan, known as Harlem, is highly populated with minority groups such as Blacks and Hispanics (New York City Population and Race, 2000), and is more impoverished than the rest of Manhattan. The demographics of Harlem and the air pollution from mobile sources such as auto traffic may be responsible for a higher asthma prevalence in Manhattan than the other boroughs. Geographical distribution of asthma data, as discussed in the following paragraph, provides a better understanding of the relationship between asthma and poverty. The significantly lower asthma rate for Long Island can be attributed to its low poverty rate and its non-proximity to the main city of New York. Long Island is about 75 miles from the city, with low automobile traffic and a sparse high income level population.

Table 4 shows a section of the summarized asthma data by zip code. As shown, some zip codes are better represented in comparison to others. Note also that there are data from other zip codes aside from New York City in the table $(93015,20002,20019,08105,08106)$, but they were not included in the final result after the data-join. Figure 1 shows a section of the resultant dataset when these data were combined with that of the New York City zip code layer. Figure 2 shows the map view of the resulting zip codes overlaying the New York City zip codes. It is important to mention that this asthma survey attempted to include a population group of ages 13-17 in a metropolitan community, rather than to target by zip code. Thus, we do not have data from all New York City zip codes. Note also that several considerably large zip codes $(10464,11696)$ are uninhabited by people, but include airports and parks. The identification of missing asthma data provides us an opportunity to make strategic decisions while planning for future asthma survey. 


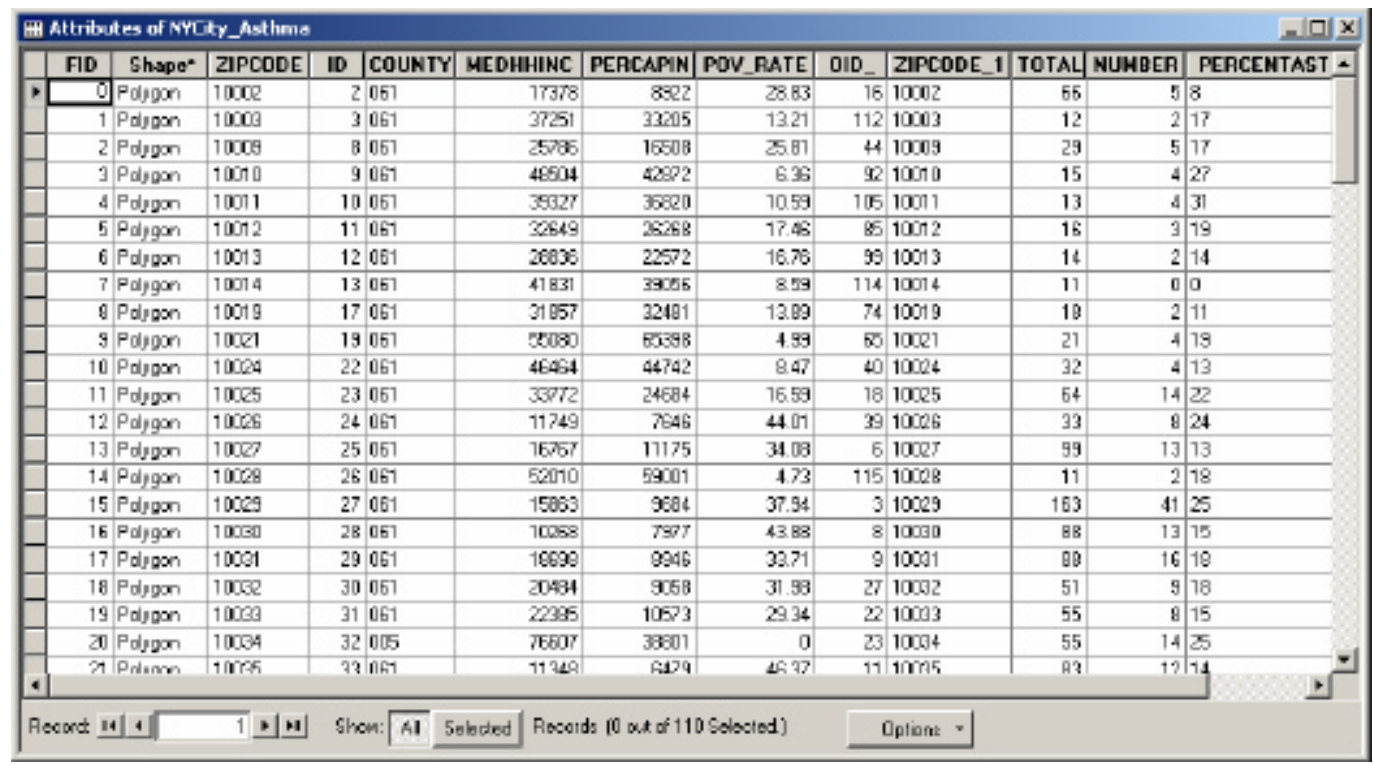

Figure 1: A section of the resultant data after joining spatial and non-spatial data, displaying two sets of zip codes

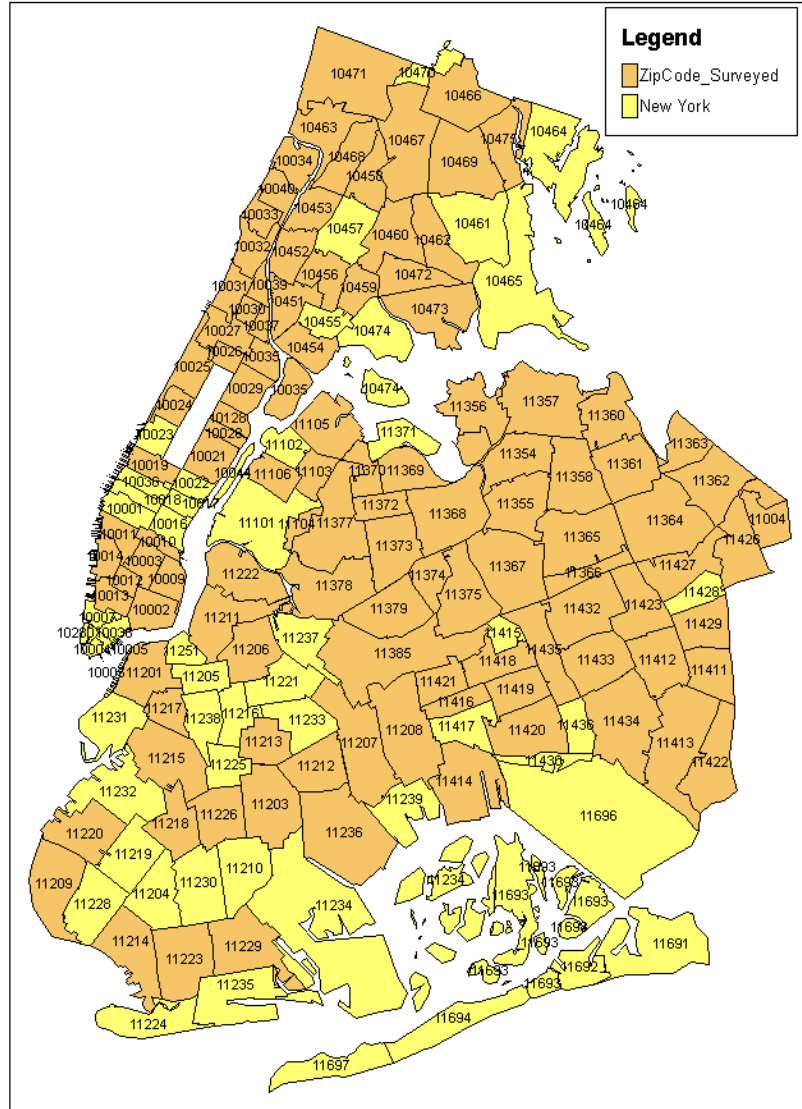

Figure 2: Resulting map at the zip code level after joining asthma data with the New York City zip code layer, displaying only four inner-city boroughs (Manhattan,

Bronx, Queens, and Brooklyn). The lighter color zip codes are missing from the survey.

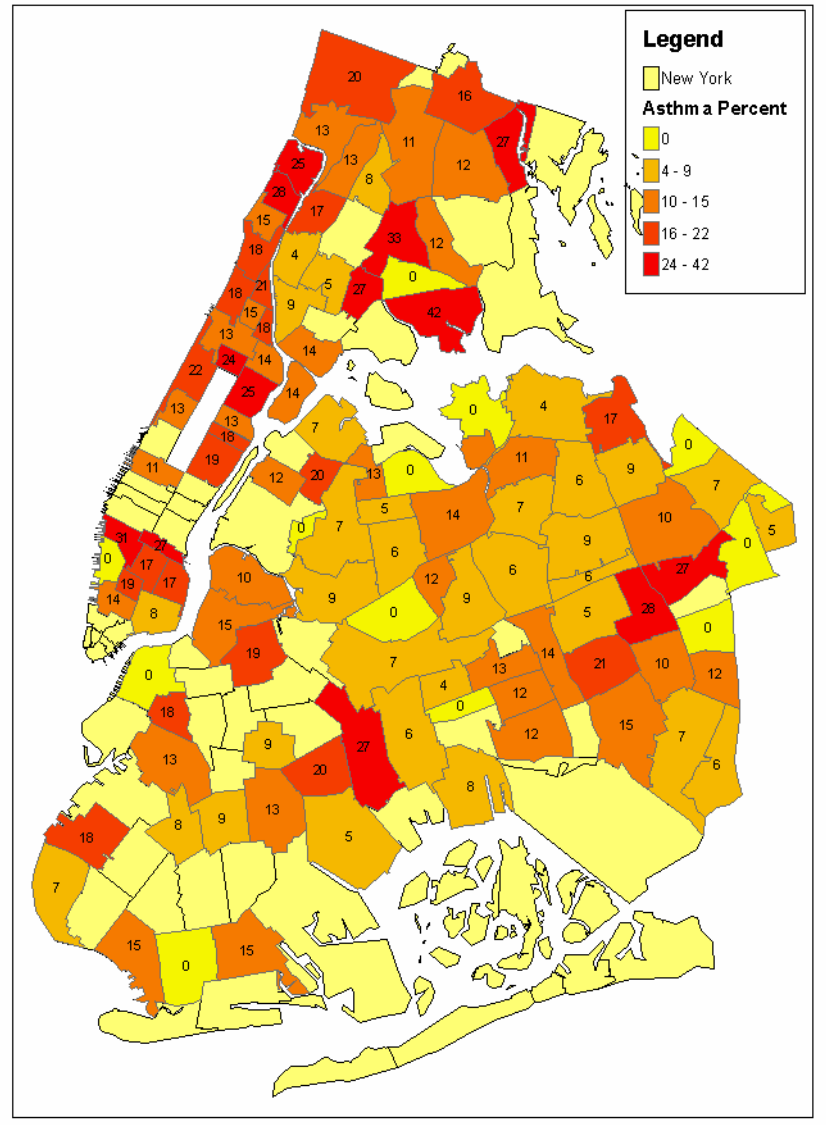

Figure 3: Resulting map at the zip code level after overlaying the asthma layer and the New York City layer for the same geographical boundary as shown in Figure 2. The darker color represents higher asthma prevalence. 
Figure 3 shows the resultant map from overlaying the asthma layer and the New York City layer. For clarity, only four inner-city boroughs are shown on the map. It is clear that, although asthma data are sporadic, our preliminary study shows that there are several concentrations of zip codes where asthma prevalence is high. These concentrations correlate well with what was reported by Claudio et al. (1999) and Gotham Gazette (2000) considering hospitalization data. However, we are missing survey data from few zip codes within the hot spots of the hospitalization data (around 10459 and 11206). Despite the missing data, data from upper and lower Manhattan (the island in the left side of Figure 3), which was represented well in the survey, shows strong correlation between our study and the hospitalization data. Further studies should focus on the missing zip codes such as 10455, 10457, and 10474 in Bronx, and 11101, 11102, 11371, 11205, 11216, 11221, 11237, 11225, 11233, 11237, 11238, and 11251 in Queens. These studies should also include more respondents from the zip codes that were underrepresented.

Figure 4 displays poverty distribution for the same zip codes used in Figure 3. A visual comparison between these two figures shows that all hot spots of asthma occurrence fall within, or very close to, the high poverty areas. Again, Manhattan, which contains the highest concentration of zip codes, shows a strong correlation between the two maps. The three large concentrations in Figure 4 - Bronx (top middle), Queens (lower middle), and upper Manhattan (top left) - are known to have high concentrations of minority populations. Lower Manhattan contains the financial district and Chinatown, representing both heavy traffic and high poverty rate. Our results confirm Claudio et al.'s (1999) argument that the asthma hospitalization data correlates well with the socioeconomic condition (median family income, percentage of minorities, and percentage of children) of the population. Correlation analysis between our asthma data (Figure 3 ) and poverty data (Figure 4) provided a correlation coefficient of 0.25 , indicating that there is some relationship between asthma and poverty. Further asthma studies on the missing zip codes will give us an opportunity to make a more definitive conclusion.

The City of New York has one of the largest crisscrossing of road, highways, and subways. Our results provide an opportunity to compare the incidence of asthma with the traffic data at the zip code level. The New York State Department of Transportation publishes traffic volume data along the major highways in all counties of New York, however they are not adaptable to GIS study at the zip code level. More survey results combined with 
the spatial distribution of traffic data will provide an opportunity to study the relationship between asthma prevalence and environmental pollution.

\section{Conclusion}

In conclusion, we have analyzed survey data that were obtained through a two-year study on asthma among approximately 4300 school children in the New York City area. The data were summarized in terms of gender, race, borough, and home zip code. Overall, in the age group 13-17 years, the asthma prevalence among males is found to be slightly higher than that of females. When comparing rates of asthma incidence among various racial groups, Blacks and Hispanics are found to have higher asthma rates than whites or Asians. Among the four main boroughs of New York City, Manhattan is found to have a slightly higher asthma prevalence than the others. Long Island, a suburb of New York, is found to have significantly lower asthma prevalence than the inner-city boroughs. We have also used a GIS tool to map asthma data at the zip code level. The result illustrates a consistent pattern of high asthma occurrence where the poverty level is high. It also correlates well with the asthma hospitalization data presented elsewhere.

\section{Acknowledgements}

I would like to thank Barbara Carlson and Cynthia Harris of Goddard Institute of Space Sciences Laboratory, New York, for providing the GIS tools and making asthma survey data available for this study. I would also like to thank NASA Summer Faculty Fellowship Program for providing me with a scholarship during my research in the summer of 2002. In addition, Lee Revere, Health Administration Lecturer at the University of Houston-Clear Lake, deserves credit for the Chi-Square analysis of data used in this study.

\section{References}

American Lung Association. (1997). Recent studies on the health effects of air pollution. Retrieved July 10, 2002 from the World Wide Web http://www.lungusa.org/press/legislative/legrecst.html

American Lung Association. (2001). Trends in air quality. Retrieved July 10, 2002 from the World Wide Web http://www.lungusa.org/data/aqp/aqp1.pdf

American Lung Association. (2002). Trends in asthma morbidity and mortality. Retrieved July 25, 2002 from the World Wide Web http://www.lungusa.org/data/asthma/ASTHMAdt.pdf

Black, S., Powers, G. \& Roche, M. (1994). A GIS-based approach to community analysis for targeted marketing. Economic Development Review, Vol. 12(2).

Bureau of Transportation Statistics. (2002). Geographical information services geospatial data. Retrieved July 3, 2002 from the World Wide Web http://www.bts.gov/gis/ntatlas/background.html

CDC: Center for Disease Control. (2002). Asthma prevalence, health care use and mortality, 2000-2001. Retrieved July 20, 2002 from the World Wide Web http://www.cdc.gov/nchs/products/pubs/pubd/hestats/asthma/asthma.htm

Claudio, L., Tulton, L., Doucette, J., \& Landrigan, P. J. (1999). Socioeconomic factors and asthma hospitalization rates in New York City. Journal of Asthma, 36(4), p.343-350.

CDPH: Connecticut Department of Public Health. (2000). A survey of the prevalence of asthma among school age children in Connecticut. Retrieved from the World Wide Web http://ehhi.org/pubs/Asthma.pdf

Clark, S. \& Shay, J. (2002). Disproportionate air pollution burden and asthma in urban communities. Retrieved July 15, 2002 from the Harvard Medical School Web site: http://www.med.harvard.edu/chge/course/papers/Clark.pdf

DHHS: Department of Health and Human Services. (May 2000). Action against asthma: A strategic plan for the Department of Health and Human Services. Retrieved July 20, 2002 from the World Wide Web http://aspe.hhs.gov/sp/asthma/ 


\section{Geographical Information Systems and Asthma}

English, P., Neutra, R., Scalf, R., Waller, L. \& Zhu, L. (1999). Examining associations between childhood asthma and traffic flow using a geographic system. Environmental Health Perspectives, Vol. 107, No. 9, p. 761-767.

ESRI: Environmental Systems Research Institute, Inc. (2002). GIS and mapping software. Retrieved July 15, 2002 from the World Wide Web: http://www.esri.com/software/index.html

Fiscal Policy Institute. (2001). Despite good economic times of the last several years, 2.5 million New Yorkers continue to live in poverty. Retrieved November 15, 2002 from the World Wide Web http://www.fiscalpolicy.org/downloads/PovertyRelease01.PDF

Francica, J. (2000). Location analysis tools help Starbucks brew up new ideas. Business Geographics, Vol. 8, No. 8, p. $32-33$.

Fung, D. S., Kung, H. \& Barber, M. C. (1995). The application of GIS to mapping real estate values. The Appraisal Journal, $v 63, \mathrm{p} 445-452$.

Gotham Gazette. (2000). Asthma Cases by Zip Code, 2000. Retrieved June 15, 2002 from the World Wide Web: http://www.gothamgazette.com/maps/asthma.shtml

Hockstra, D. \& Mattejat, P. (2002). Manage drainage infrastructure. Public Works, Vol. 133, No. 5, p.170-171.

Institute on Climate and Planets. (June 2002). UrbanMAAP asthma survey project. Retrieved June 03, 2002 from the World Wide Web: http://icp.giss.nasa.gov/research/urbanmaap/asthma.html

Jacquez, G. (2000). Spatial analysis in epidemiology: Nascent science or a failure of GIS? Journal of Geographical Systems, Vol. 2, p. 91-97.

Johnson, M. L. (1995). GIS in business: issues to consider in curriculum decision-making. Journal of Geography, Vol. 98, p. $105+$.

Lara, M., Rosenbaum, S., Rachelefsky, G., Nicholas, W., Morton, S. C., Emont, S., Branch, M., Genovese, B., Vaiana, M. E., Smith, V., Wheeler, L., Platts-Mills, T., Clark, N., Lurie, N. \& Weiss, K. B. (2002). Improving childhood asthma outcomes in the United States: A blueprint for policy action. Pediatrics, Vol. 109, p. 919-930.

Lubenow, A. \& Tolson, K. (2001). GIS technology helps pinpoint patients. Health Management Technology, v 222 No.1, p.54-55.

Mann, J. (2000). Asthma in San Francisco. San Francisco Department of Public Health.

Nemeth, D. (2001). GIS shows how data becomes a vital corporate asset. Pipeline \& Gas Journal, Vol. 228, No. 3, p. 41- 43.

New York City Department of Planning. (2002). 2000 Census Summary. Retrieved November 15, 2002 from the World Wide Web: http://www.ci.nyc.ny.us/html/dcp/html/census/pop2000.html

New York City Population and Race. (2000). Retrieved November 15, 2002 from the World Wide Web: http://130.166.124.2/ny 1. html

Saccomano, A. (1998). Shape of supply chain. Traffic World, v 254, No. 10, p. 34-36.

Smith, C. A. \& Webb, J. R. (1997). Using GIS to improve estimates of future retail space demand. The Appraisal Journal, October, p. 337-341.

Texas General Land Office. (2002). Geographic information systems data from the Texas General Land Office. Retrieved June 15, 2002 from the World Wide Web: http://www.glo.state.tx.us/gisdata/gisdata.html

USC: University of Southern California. (2002). USC study shows air pollution may trigger asthma in young athletes. HSC Weekly, Vol.8, No.3.

Vine, M. F., Degnan, D. \& Hanchette, C. (1998). Geographic information systems: Their use in environmental epidemiologic research. Journal of Environmental Health, Vol. 61, No. 3, p. 7-16.

Walsham, G. \& Sahay, S. (1999). GIS for district-level administration in India: Problems and opportunities. MIS Quarterly, V 23, No. 1, p. 39-65.

Weigel, D. \& Cao, B. (1999). Applying GIS and OR techniques to solve sears technician-dispatching and home-delivery problems. Interfaces, Vol. 29, No. 1, p.112-130.

Wier, K. R. \& Robertson, J. G. (1998). Teaching geographic information systems for social work applications. Journal of Social Work Education, Vol. 34(1), p. 81-96. 


\section{Biography}

Mohammad A. Rob is an Assistant Professor of Management Information Systems at the University of Houston-Clear Lake (UHCL). Before joining UHCL, he has worked as a programmer/analyst in several companies and participated in the development and management of multiple information systems. He teaches courses such as systems analysis and design, e-commerce technology, active server pages, and IT project management. He is very active in curriculum development and his current areas of research include e-commerce technology, online payment mechanisms, and geographical information systems. 